CASE REPORTS

\title{
Sustained release bupropion overdose: an important cause of prolonged symptoms after an overdose
}

\section{F Jepsen, J Matthews, F J Andrews}

Emerg Med J 2003;20:560-561

The case is reported of a patient who had taken a deliberate overdose of sustained release bupropion. The patient suffered from prolonged symptoms including seizures before fully recovering. The prescription of bupropion is encouraged as an aid to smoking cessation and it is probable that bupropion overdose will become more common. Emergency departments need to be aware that patients taking an overdose of sustained release bupropion may have a delayed onset and prolonged course of symptoms. The pharmacology, clinical features, and treatment of bupropion overdose are discussed.

A 27 year old woman presented to the emergency department (ED) after a deliberate overdose of $59 \times 150 \mathrm{mg}$ sustained release bupropion tablets three hours earlier. No other drug or alcohol had been ingested. These tablets had been prescribed by her general practitioner to aid smoking cessation. The patient had a history of depressive illness and asthma, she was not known to be taking any recreational drugs, and had not previously taken an intentional overdose or expressed any suicidal thoughts.

On examination the eyes were open, she obeyed commands, and was orientated to time and place (GCS 15/15). The patient complained of dizziness but no nystagmus was detected. Pupils were $4 \mathrm{~mm}$ and neurological examination revealed no focal abnormalities and no hyper-reflexia. An electrocardiogram revealed a sinus tachycardia (120 beat/ min) with no QRS or QTc abnormality, and blood pressure was measured as 141/62. Laboratory investigations revealed a glucose of $6.3 \mathrm{mmol} / \mathrm{l}$, sodium $145 \mathrm{mmol} / \mathrm{l}$, potassium $4.0 \mathrm{mmol} / \mathrm{l}$, corrected calcium $2.43 \mathrm{mmol} / \mathrm{l}$, magnesium $0.94 \mathrm{mml} / \mathrm{l}$, and no detectable paracetamol or salicylate. Arterial blood gas measurements taken two hours after ED admission revealed no evidence of a metabolic acidosis ( $\mathrm{pH}$ 7.433, $\mathrm{PCO}_{2} 4.68 \mathrm{kPa}, \mathrm{PO}_{2} 11.5 \mathrm{kPa}, \mathrm{HCO}_{3} 23.8 \mathrm{mmol} / \mathrm{l}$ ).

The patient complained of severe nausea and vomited several times shortly after arrival in the ED. Because of the delay in presentation, no gastric lavage was performed and no activated charcoal was administered. One hour after admission to the ED, she had a generalised tonic-clonic seizure, lasting two minutes, which stopped spontaneously, with a brief post-ictal period. She then suffered two further seizures over the next two hours, the first was self terminating after one minute but the second seizure required treatment with $10 \mathrm{mg}$ of intravenous diazepam. She was transferred to the high dependency unit (HDU) for further treatment. While in the HDU she appeared to be experiencing visual hallucinations that responded to verbal reassurance and did not require further treatment. The patient had two further self terminating seizures, lasting for 20 seconds; the last one occurring 10 hours after the overdose. In view of the short duration of the seizures and the expected elimination of the bupropion, prophylactic anticonvulsant therapy was not deemed to be necessary. The patient was asymptomatic upon discharge two days after admission, with psychiatric follow up arranged.

\section{DISCUSSION}

The UK Medicines Control Agency licensed sustained release bupropion in 2000 as an aid to cigarette smoking cessation. ${ }^{12}$ The UK Health Education Authority (HEA) and the UK National Institute for Clinical Excellence (NICE) also recommend bupropion for smokers who wish to quit. ${ }^{34}$ Bupropion is a unique monocyclic antidepressant, with structural similarities to amphetamines. It weakly inhibits neuronal reuptake of dopamine, norepinephrine, and seretonin and has moderate anticholinergic activity. In smoking cessation it is believed to act by increasing dopamine concentration in the nucleus accumbens. ${ }^{5}$ Therapeutic peak plasma values are reached within three hours of ingestion with a mean elimination half life of 21 hours; bupropion is extensively metabolised by multiple pathways with no single pathway predominating. ${ }^{6}$ At therapeutic doses, dry mouth and insomnia are common side effects but seizures occur in about $0.1 \%$ of patients. ${ }^{127}$

Table 1 summarises the features of bupropion overdose. The range of overdose symptoms overlaps with that of amphetamine misuse, 3,4-methylenedioxymethamphetamines (MDMA (ecstasy)) ingestion, and tricyclic antidepressant overdose. Hallucinations, agitation, and seizures ${ }^{8}$ are the commonest central nervous system effects after an overdose, but physical signs of anticholinergic intoxication such as mydriasis and hyperreflexia are rarely present. Seizures occur in $21 \%$ of cases ${ }^{9}$ and up to 14 hours after overdose. ${ }^{10}$ With the exception of tachycardia, other cardiac manifestations are uncommon, but overdose with more than $1.5 \mathrm{~g}$ has been associated with intraventricular conduction disturbance ${ }^{11}$ and prolongation of the QTc interval. ${ }^{12}$ Arrythmias and cardiac

Table 1 Features of bupropion toxicity

\begin{tabular}{ll}
\hline System & Features \\
\hline Cardiovascular & Tachycardia \\
& Prolonged QRS \\
& Prolonged QTc \\
& Electromechanical dissociation \\
Neurological & Seizures \\
& Tremors \\
& Visual hallucinations \\
& Agitation \\
& Perceptual alterations \\
& Parasthesia \\
& Light headedness \\
& Coma \\
& Confusion \\
Gastrointestinal & Nausea \\
& Vomiting \\
\hline
\end{tabular}


arrest $^{13}$ have occurred with massive overdoses; death is rare but has followed ingestion of $10 \mathrm{~g}$ or more. ${ }^{14}{ }^{15}$ Treatment of an overdose of sustained release bupropion is supportive, as there is no antidote available. ${ }^{16}$ Gastric lavage ${ }^{17}$ and oral activated charcoal ${ }^{18}$ may be considered within an hour of overdose; but the value of further doses of charcoal or whole bowel irrigation in bupropion overdose has not been established. Seizures are often short lived; benzodiazepines may be required for seizure control and hallucinations but antipsychotics should be avoided as these lower the seizure threshold. Electrocardiographic abnormalities usually resolve without treatment although adenosine has been successfully used to treat broad complex tachycardia resulting from massive overdose..$^{13}$

Within two months of this patient being treated, another patient presented to our ED after an overdose of sustained release bupropion with similar central nervous system symptoms but no overt cardiotoxicity, followed by a full recovery. Overdose of this drug may become more common ${ }^{19}$ with increasing therapeutic use and EDs need to be aware of its adverse effects even in therapeutic dose. ${ }^{20}$ We suggest that patients should be observed for at least 12 hours to detect delayed central nervous system excitement after sustained release bupropion overdose; patients should receive cardiac monitoring until the accompanying tachycardia has abated and any QRS or QTc interval prolongation has been excluded.

\section{Contributors}

FJ initiated the idea, performed a literature search and wrote the paper. JM initiated the idea and helped with writing the paper. FJA reviewed the literature, reviewed the manuscript and helped with writing the paper. FJ acts as the guarantor of the paper. We acknowledge the staff of the National Poisons Information Service, Cardiff, United Kingdom for their advice regarding the management of this patient

\section{Authors' affiliations}

F Jepsen, J Matthews, Accident and Emergency Department, Whiston Hospital, Prescot, UK

F J Andrews, Intensive Care Department, Whiston Hospital

Funding: none.

Conflicts of interest: none declared.
Correspondence to: Dr F Jepsen, Accident and Emergency Department, Whiston Hospital, Prescot L35 5DR, UK; fiepsen@bigfoot.com

Accepted for publication 3 January 2003

\section{REFERENCES}

1 Hurt RD, Sachs DP, Glover ED, et al. A comparison of sustained-release bupropion and placebo for smoking cessation. N Engl J Med 1997;337: 1195-202

2 Jorenby DE, Leischow SJ, Nides MA, et al. A controlled trial of sustainedrelease bupropion, a nicotine patch, or both for smoking cessation. N Engl J Med 1999;340:685-91.

3 West R, McNeill A, Raw M. Smoking cessation guidelines for health professionals: an update. Thorax 2000;55:987-99.

4 National Institute for Clinical Excellence. Guidance on the use of nicotine replacement therapy and bupropion for smoking cessation. London: NICE, 2002.

5 Ascher JA, Cole JO, Colin NJ, et al. Bupropion: a review of its mechanism of antidepressant activity. J Clin Psychiatry 1995;56:395-401.

6 Johnston AJ, Ascher J, Leadbetter R, et al. Pharmacokinetic optimisation of sustained-release bupropion for smoking cessation. Drugs 2002;62(suppl 2): 11-24.

7 GlaxoSmithKline. Zyban (bupropion hydrochloride) sustained-release tablets: product information. Welwyn: GlaxoSmithKline, 2001.

8 Mainie I, McGurk C, McClintock G, et al. Seizures after bupropion overdose. Lancet 2001;357:1624.

9 Spiller HA, Ramoska EA, Krenzelok EP, et al. Bupropion overdose: a 3-year multi-center retrospective analysis. Am J Emerg Med 1994;12:43-5.

10 Sigg T. Recurrent seizures from sustained-release bupropion. Int J Med Toxicol 1999;2:4.

11 Paris PA, Saucier JR. ECG conduction delays associated with massive bupropion overdose. J Toxicol Clin Toxicol 1998;36:595-8.

12 Shrier M, Diaz JE, Tsarouhas N. Cardiotoxicity associated with bupropion overdose. Ann Emerg Med 2000;35:100.

13 Tracey JA, Cassidy N, Casey PB, et al. Bupropion (Zyban) toxicity. Ir Med J 2002;95:23-4.

14 Friel PN, Logan BK, Fligner CL. Three fatal drug overdoses involving bupropion. J Anal Toxicol 1993;17:436-8.

15 Harris CR, Gualtieri J, Stark G. Fatal bupropion overdose. J Toxicol Clin Toxicol 1997;35:321-4.

16 White RS, Langford JR. Sustained release bupropion: overdose and treatment. Am J Emerg Med 2002;20:388-9.

17 American Academy of Clinical Toxicology; European Association of Poisons Centres and Clinical Toxicologists. Position statement: gastric lavage. Clin Toxicol 1997;35:711-19.

18 American Academy of Clinical Toxicology; European Association of Poisons Centres and Clinical Toxicologists. Position statement: single-dose activated charcoal. Clin Toxicol 1997;35:721-41.

19 Bhattachariee C, Smith M, Todd F, et al. Bupropion overdose: a potential problem with the new 'miracle' anti-smoking drug. Int J Clin Pract 2001;55:221-2.

20 Pesola GR, Avasarala J. Bupropion seizure proportion among new-onset generalized seizures and drug related seizures presenting to an emergency department. J Emerg Med 2002;22:235-9. 